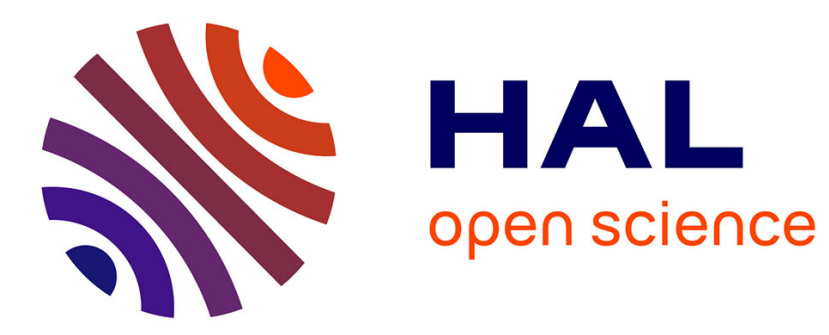

\title{
Ceilometer inversion method using water-vapor correction from co-located microwave radiometer for aerosol retrievals
}

Andres E. Bedoya-Velásquez, Marcos Herreras-Giralda, Roberto Román, Matthias Wiegner, Sidonie Lefebvre, Carlos Toledano, Thierry Huet, Romain Ceolato

\section{To cite this version:}

Andres E. Bedoya-Velásquez, Marcos Herreras-Giralda, Roberto Román, Matthias Wiegner, Sidonie Lefebvre, et al.. Ceilometer inversion method using water-vapor correction from co-located microwave radiometer for aerosol retrievals. Atmospheric Research, 2021, 250, pp.105379. 10.1016/j.atmosres.2020.105379 . hal-02865809v2

\section{HAL Id: hal-02865809 \\ https://hal.science/hal-02865809v2}

Submitted on 12 Jan 2021

HAL is a multi-disciplinary open access archive for the deposit and dissemination of scientific research documents, whether they are published or not. The documents may come from teaching and research institutions in France or abroad, or from public or private research centers.
L'archive ouverte pluridisciplinaire HAL, est destinée au dépôt et à la diffusion de documents scientifiques de niveau recherche, publiés ou non, émanant des établissements d'enseignement et de recherche français ou étrangers, des laboratoires publics ou privés. 


\title{
Ceilometer inversion method using water-vapor correction from co-located microwave radiometer for aerosol retrievals
}

\author{
A. E. Bedoya-Velásquez ${ }^{\mathrm{a}}$, M. Herreras-Giralda ${ }^{\mathrm{b}, \mathrm{c}}$, R. Román ${ }^{\mathrm{d}}$, M. Wiegner $^{\mathrm{e}}$,

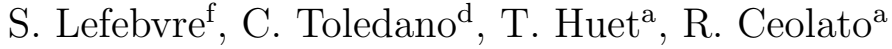 \\ ${ }^{a}$ The French Aeorospace Lab, ONERA, Toulouse, France \\ ${ }^{b} G R A S P-S A S$, Remote sensing developments, Université des Sciences et Technologies de \\ Lille, Villeneuve d'Ascq, France \\ ${ }^{c}$ Laboratoire d'Optique Amosphérique, Université des Sciences et Technologies de Lille, \\ Villeneuve d'Ascq, France \\ ${ }^{d}$ Grupo de óptica atmosférica, Universidad de Valladolid, Valladolid, Spain \\ ${ }^{e}$ Meteorologisches Institut, Ludwig-Maximilians-Universität, Theresienstraße 37, 80333 \\ München, Germany \\ ${ }^{f}$ The French Aeorospace Lab, ONERA, Palaisseau, France
}

\begin{abstract}
Recent ceilometer models are more sensitive to aerosols, which is increasing the interest in these instruments to retrieve aerosol optical and microphysical properties. In this paper, a new methodology is proposed to retrieve aerosol vertical extinction and backscatter profiles from a Vaisala ceilometer CL51 model. This methodology is based in two parts: first, a signal preprocessing with a suppression of the dark current and background noises, and a correction of the water vapor absorption using near-real-time temperature and absolute humidity $(\mathrm{AH})$ profiles from a co-located Microwave radiometer (MWR). The measured dark current shows a height-dependence from $11 \mathrm{~km}$ agl to the end of the profile. From the water vapor correction, it was seen that the raw ceilometer signal overestimates the water vapour corrected one, mainly below $1 \mathrm{~km}$ agl. Second part is based on an iterative Klett-based algorithm making use of AERONET (AErosol RObotic NETwork) AOD (Aerosol Optical Depth) and ceilometer profiles as inputs to retrieve the extinction and backscatter profiles. The sensitivity of the aerosol retrievals to the use of modelled temperature and absolute humidity from HYSPLIT to correct water vapor absorption, instead of MWR measurements, is studied. The absolute errors found in temperature and AH profiles
\end{abstract}


leads to errors in the pre-processed range corrected signals up to $9 \%$, and then in particle backscatter $\left(\beta_{p}\right)$ and particle extinction $\left(\alpha_{p}\right)$ coefficients up to $2.2 \%$ and $25 \%$, respectively.

Keywords: Aerosol inversion, Vaisala ceilometer, microwave radiometry, ceilometer data pre-processing

\section{Introduction}

Atmospheric aerosols play a crucial role in atmospheric dynamics and the energy balance of the Earth. The main impact of the aerosols relatedinteractions are: (i) the aerosol-radiation interaction (ARI), affecting the radiative fluxes of the Earth by absorbing and scattering solar and thermal radiation, and (ii) aerosol-cloud interaction (ACI) which are mainly associated to the modification of cloud properties and precipitation caused by aerosols ([1]).During the last decades, different active and passive remote sensors in synergistic operation have become a powerful strategy for the better determination of the atmospheric aerosol properties (optical and microphysical). Previous works have shown that synergy between active remote sensors as lidar systems (light detection and ranging) and passive remote sensors, e.g. sunphotometers or microwave radiometer (MWR), allows to obtain advanced and vertically resolved aerosol properties $([2,3,4,5])$ and to study phenomena like aerosol hygroscopic growth $([6])$ and the aerosol vertical dynamics using as proxy the planetary boundary layer (PBL) height ([7]). The main drawbacks of these synergies are the cost of having the instrumentation operating together and also that most of the instruments are semi-automatic, which means that qualified human operation is frequently needed.

Ceilometers are low power single-wavelength lidar-based instruments which operate automatically, unattended and continuously. These instruments are commonly used for cloud base height determination and PBL studies, but recently, ceilometers have become an useful alternative for aerosol studies such as typical robust lidar instruments. These systems have been widely spread along the world with more than 1000 ceilometers installed over Europe, Asia and America. Currently, the COST Action ES1303 TOPROF (TOwards operational ground based PROFiling with ceilometers, doppler lidars and microwave radiometers for improving weather forecasts) has dedicated part of their interests on working in a better characterization of the ceilometer 
products and related uncertainties, and also E-PROFILE, a program of EUMETNET (EUropean METeorological services NETwork), is focused on the harmonization of ceilometer measurements and data provision across Europe, meaning that the interest in quantitative aerosol products from these instruments is increasing. In the last decade, ceilometers started to be used for long term studies of phenomena less investigated with remote sensors like aerosol hygroscopic growth ([8]), to improve the forecasting models for example to predict fog events ([9]), to retrieve profiles of aerosol properties $([10,11,12,13]$ and to characterize them $([14]$ and $[15])$.

CHM15k ceilometer model (Lufft manufacturer) is widely used for aerosol inversion, mainly because it operates with a similar configuration as the commercial lidar systems, therefore the quality of the signals have been deeply studied and their capabilities are well known $[12,13]$. Other ceilometers used for the same end are the CL31 and CL51 models (Vaisala Inc.), but as it has been shown in [16], depending of the firmware and other features, Vaisala ceilometers present some drawbacks such as non-expected signal shapes and high electronic noises. In [17] is presented a new type of correction that improves the signal shape, named dark signal removal, making a substitution of the dark current measurements. In addition, as the emission line of the Vaisala CL-51 ceilometer is centered around $910 \mathrm{~nm}$, water vapor absorption plays a critical role affecting the quality of the signal. [18] describes a methodology to make a water vapor correction of the signal using modelled water vapor absorption cross section and radiosondes for retrieving aerosol properties. After considering all this pre-processing, it is possible to use the ceilometer signal for aerosol retrieval using traditional methods such as the Klett's algorithm $([19,12])$.

The main objective of this work is to present a new methodology, based on a modified Klett algorithm [12], to retrieve optical aerosol properties from Vaisala CL51 ceilometers. To this end, a data pre-processing is required, including the suppression of the dark current noise (DCN), height-dependant background (BG) noises, and water vapor correction in near-real time by using a co-located microwave radiometer (MWR). The methodology allows to determine the error propagation when modelled atmospheric profiles are used for aerosol inversion products instead of using co-located measurements.

The manuscript is organized as follows. The site, instrumentation and 
data used are presented in Section 2, while Section 3 explain the applied methodology in terms of the signal pre-processing. Section 4 describes the Klett method to retrieve the aerosol profiles, and Section 5 shows the uncertainty in the retrievals caused by the use of water vapor derived from modelled radiosoundings instead of MWR data. Finally, Section 6 summarizes the main conclusions.

\section{Site, Instrumentation and data availability}

\subsection{ONERA site}

ONERA, the French Aerospace Lab, is a research institute located in Toulouse, Occitanie, in the southern part of France (N: 43 34'12", E: 128'24"). The mission of the Optictronics department (DOTA) is to conduct studies and research in Optronics. These studies are conducted primarily for the benefit of the fields of Aeronautics, Space and Defence, but also for other fields such as security, environment, astronomy and medical imaging. MELOPEE Lab is a light-scattering lidar laboratory dedicated to the development of active remote-sensing instrument for light-scattering investigations. For this work, a ceilometer and a ground-based microwaver radiometer located on roof-top of the building were used for this experiment. Toulouse is a region with a humid subtropical climate dominated by Autan wind, which is a south-easterly wind from the Mediterranean. Due to the Garone river that divides the city between east and west crossing it from south to north, Toulouse presents rather high relative humidity (around 80\%) almost all over the year. The seasonal behaviour drives to have hot summers and cold winters.

\subsection{Vaisala CL51 ceilometer}

A CL51 Vaisala ceilometer, located at the ONERA site, have been used in this work. This is an active remote sensor that operates continuously $(24 / 7)$ emitting pulsed laser radiation towards the atmosphere centered at $910 \pm 10 \mathrm{~nm}$. The backscattered radiation by the atmosphere is collected by a telescope in coaxial configuration, reducing the overlap height.Unless the ceilometer is a new instrument with less than a year to be installed and the fact that manufacturer provided an overlap information that assures full-overlap after $50 \mathrm{~m}$, we have considered our products above $250 \mathrm{~m}$ agl because this work is not focused in the near-field measurements. The detection system is based on an APD detector. The backscattered signal from the atmosphere is measured with spatial and temporal resolutions up to $10 \mathrm{~m}$ 
and 15 s respectively. More technical information can be found in [16]. The spectral range of the emitted and received light by the instrument is affected by atmospheric water vapor absorption, which has a direct impact on the recorded attenuated backscatter profile, which is the main product of the instrument.

Considering a single scattering approximation and assuming that lidar constant $(\mathrm{K})$ and overlap $(\mathrm{O}(\mathrm{R}))$ are well known, the ceilometer retrieved signal based on the elastic lidar equation can be written as follows:

$$
\frac{R C S(R)}{K_{0} O(R)}=U(R)=\beta(R) \exp \left[-2 \int_{0}^{R} \alpha(r) \mathrm{d} r\right]
$$

where $\mathrm{RCS}(\mathrm{R})$ is the range corrected signal (the recorded signal divided by the square of range); $\mathrm{K}_{0}$ is a constant that involves system characteristics (optics and electronics); $\mathrm{O}(\mathrm{R})$ is the overlap function referring to the geometrical probability of fully signal collection as a function of height; $\beta$ is the backscatter coefficient. The double pathway atmospheric transmittance is defined as $\mathrm{T}^{2}(R)=\exp \left[-2 \int_{0}^{R} \alpha(r) \mathrm{d} r\right]$ where $\alpha$ is the atmospheric extinction coefficient. In a general formulation, $\beta$ and $\alpha$ takes into account the contribution of the particles and molecules in the atmosphere [20, 19].

The $U(R)$ term is the main product retrieved from ceilometers, but in practice this coefficient cannot be always determined because $\mathrm{K}_{0}$ and $\mathrm{O}(\mathrm{R})$ parameters are unknown most of the time. Due to this elastic lidar formulation, the wavelength dependency is omitted from the equations. The analytical solution of the Eq.1 can be obtained by using Klett-Fernald method $([20,19])$ assuming a constant extincton-to-backscatter ratio, also known as lidar ratio $(L R)$. Other atmospheric parameters are involved in the solution of the lidar equation, but those will be discussed in further sections. The data used in this work were measured continuously from October to November 2019 with temporal resolution about $36 \mathrm{~s} /$ profile and vertical resolution of $10 \mathrm{~m}$ (from $10 \mathrm{~m}$ to $15400 \mathrm{~km}$ agl). The instrument records 2400 measures per day of RCS profiles, but it also provides cloud base height, and other metadata.

\section{3. $R P G-H A T P R O M W R$}

A ground-based microwave radiometer (RPG-HATPRO, Radiometer physics $\mathrm{GmbH}$ ) is co-located to the mentioned ceilometer. MWR is considered as a 
passive remote sensor that performs measures unattended of the brightness temperatures of oxygen and water vapor in the atmosphere. The oxygen is measured in the $\mathrm{K}$-band $(51-58 \mathrm{GHz})$ and the water vapor in the V-band from 22 to $31 \mathrm{GHz}$ with a radiometric resolution between 0.3 and $0.4 \mathrm{rms}$ errors at $1.0 \mathrm{~s}$ integration time.

A previously trained neural network algorithm ([21]) is used to retrieve temperature and relative humidity $(\mathrm{RH})$ and absolute humidity $(\mathrm{AH})$ profiles. The temperature and $\mathrm{RH}$ profiles are provided at 92 height bins with variable vertical resolution and covering the first $10 \mathrm{~km}$ of the atmosphere. Temperature and RH profiles performance (accuracy and precision) has been studied in previous studies using radiosondes as references and finding that the temperature accuracy and precision is up to $1 \pm \mathrm{K}$ and close to $6 \pm 8$ $\%$ for RH under cloud-free conditions [22]; this pointed out the potential of these systems to retrieve atmospheric variables. Regarding the data availability for this study, the MWR provides up to 600 temperature, relative humidity and absolute humidity profiles per day with temporal resolution up to $2 \mathrm{~min} /$ profile. Temperature profiles had a composite format that combined the high spatial resolution of the atmospheric boundary layer profiles product with the standard temperature profiles.

\subsection{CIMEL sun/sky photometer}

A sun/sky photometer CIMEL CE318-N (Cimel Electronique S.A.S.)([23]) is operating since 2013 at the south-east part of Toulouse $(43.57 \mathrm{~N}, 1.37 \mathrm{E}$, at $160 \mathrm{~m}$ asl), up to $8 \mathrm{~km}$ away from the ceilometer in straight line. This instrument provides automatic measurements of sun and sky radiation at several wavelengths $(340,380,440,500,675,870,940,1020$ and $1640 \mathrm{~nm})$. These measurements are processed by AERONET in order to derive the optical and microphysical aerosol properties integrated in column [23]. The main AERONET product is the spectral aerosol optical depth $\left(A O D_{\lambda}\right)$. In addition, the channel of $940 \mathrm{~nm}$ is used for retrieving the total column water vapor (or precipitable water vapor). AERONET also uses $A O D_{\lambda}$ and almucantar sky radiance measurements to retrieve and provide additional aerosol properties including volume size distribution, complex refraction index, and single scattering albedo at various wavelengths $([24,25,26])$.In this work, the AERONET AOD data used is the AERONET level 1.5 (cloud-screened) from AERONET version 3 ([27]), with an uncertainty lower than \pm 0.01 for the wavelengths larger than $440 \mathrm{~nm}$ and below 0.02 for shorter wavelengths. 


\subsection{Hysplit GDAS meteorological data base}

As a result of the computer analysis and forecast calculation performed at the centers for Environmental prediction (NCEP), it is possible to use an operational system so called Global Assimilation Data System (GDAS) for running the Hybrid Single Particle Lagrangian Integrated Trajectory Model (HYSPLIT)([28]). One of the HYSPLIT modules allows to retrieve modelled radiosondes with different spatial and temporal resolutions. In this work, we have retrieved HYSPLIT profiles of temperature, relative humidity and pressure for ONERA location with spatial resolution of 0.5 and $3 \mathrm{~h}$ of temporal resolution. The total database of radiosoundings used for this study is 488 profiles (October and November 2019) from 0 to $10 \mathrm{~km}$.

\section{Signal pre-processing}

The methodology developed in this paper involves the following 2 stages (Fig.1): (i) the signal pre-processing: contain dark current (DC), background (BG) and water vapor correction by using real co-located atmospheric measurements and (ii) refers to the semi-automatic Klett algorithm.

\subsection{Dark current correction}

First, a ceilometer data pre-processing is performed. For signal noise correction, two types of signal are taken into account. The first one is linked with the electrical noise of the detectors which is so called dark current noise (DCN). In this work, DCN measurements were carried out under day-time and night-time conditions using the termination hood accessory delivered with the ceilometer shipping for covering the instrument to avoid external light contamination, however some reflections in the near field are still remained (below 50m). The DCN was regularly measured twice per week during two weeks, taking samples of 30 minutes at day and night time.During the analyzed period (October-November 2019) DCN does not show a high variability between days, therefore we focused our attention on the day-time and night-time analysis. As example, Fig.2a presents the day-time(gray line) and night-time (black line) mean DCN profiles measured from $0.010 \mathrm{~km}$ to $15.4 \mathrm{~km}$ agl for the $11^{\text {th }}$ October 2019. The bias between the profiles (not shown) in the first kilometers after full overlap (from $0.80 \mathrm{~m}$ to $1 \mathrm{~km}$ agl) is close to zero, but it increased rapidly with height: bias from 1 to $2 \mathrm{~km}$ agl increased from 2.5 to $5.0 \mathrm{a}$.u, from 2 to $6 \mathrm{~km}$ agl increased from 5 to $25 \mathrm{a} . \mathrm{u}$ and above this height the bias reached up values above 300 a.u. The shape 


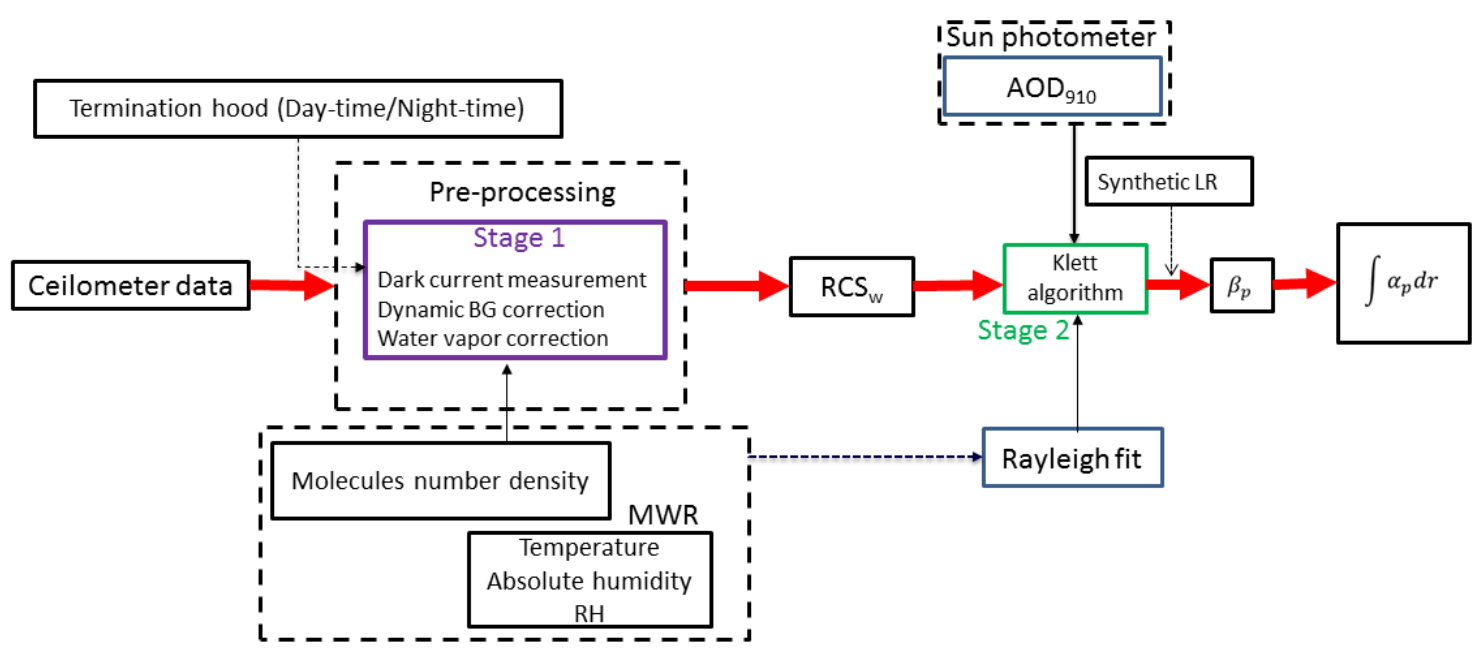

Figure 1: Block diagram of the methodology

of the DCN signal is relatively well balance between negative and positive values around zero until $9 \mathrm{~km}$ agl (see Fig.2b), but above this height the signal is fluctuating strongly describing a S-shape. From 9 to $11 \mathrm{~km}$ agl positive curve can be observed, then the signal decrease from 11 to $14 \mathrm{~km}$ agl describing a negative curve for finally increase again from $14 \mathrm{~km}$ to the end of the profile. To focus the attention in the shape of the DCN, we plotted the smoothed the DCN in Fig.2b, observing that the noise is quite oscillating around zero for daytime (due to the light contamination) than night-time, but the shape remains. Once the DCN is characterized, it must be directly subtracted from the range corrected ceilometer raw data.

According to [16] results, this behavior can be expected for Vaisala ceilometers, however this analysis let us evidence the impact that DCN suppression will have on the $R C S_{\text {raw }}$ signal. The signal-to-noise ratio (SNR) of this instrument decrease above $4 \mathrm{~km}$ agl, which was checked for the raw signal (not shown) and range corrected (see Fig.2c). The $R C S_{\text {raw }}$ signal shown in 

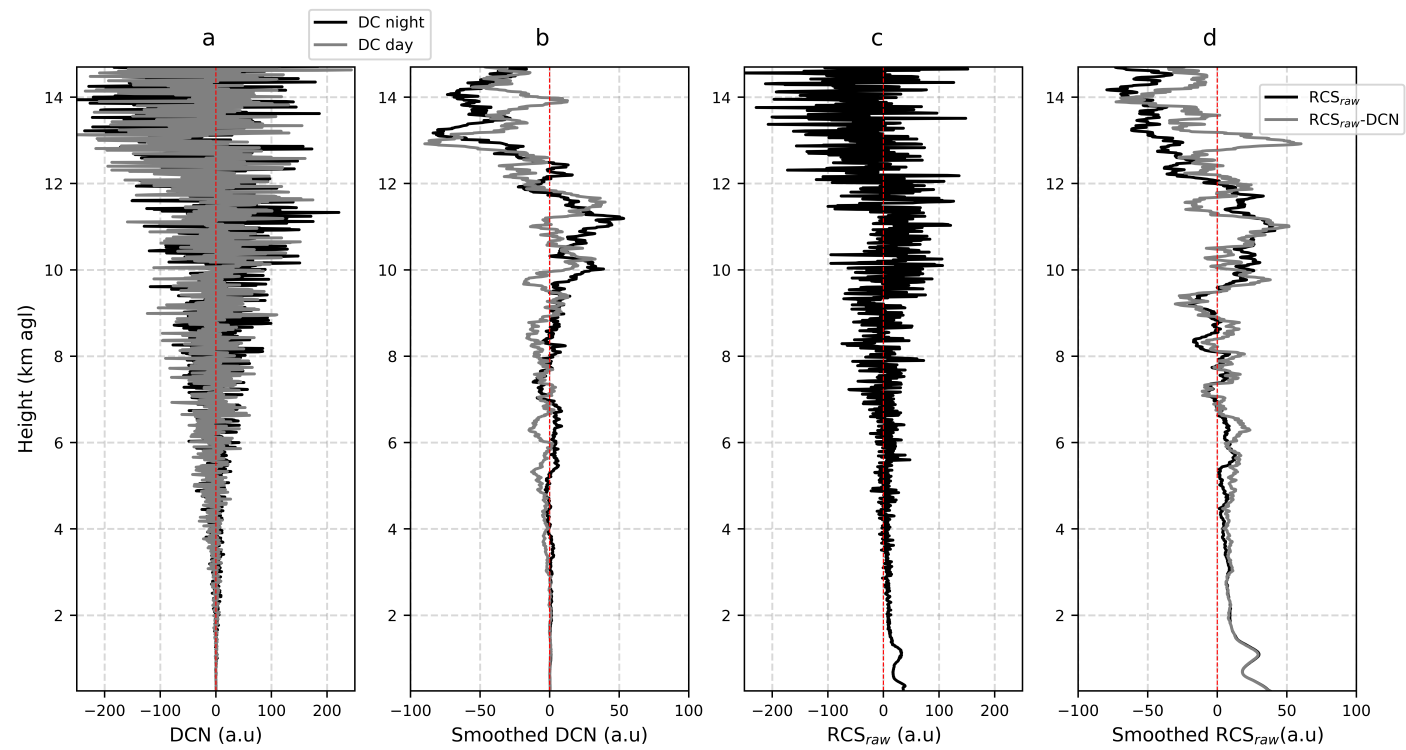

Figure 2: Example measurements corresponding to $11^{\text {th }}$ October 2019. Here, the ceilometer DCN correction is shown. a) The DCN measurements are presented in black: night-time and gray: day-time; b) the smoothed DCN smoothed profiles (for the sake of clarity, but not considered in the calculations); c) the $R C S_{\text {raw }}$ signal 1h-averaged, and d) the $R C S_{\text {raw }}$ DCN corrected (smoothed)

Fig.2b was $1 \mathrm{~h}$-averaged in order to minimize spatial fluctuations. Testing with the $R C S_{\text {raw }}$, it was possible to determine that the $R C S_{\text {raw }}$ and DCN keep the same shape from $7 \mathrm{~km}$ agl until the maximum range of the profile, which give us the possibility to minimize these fluctuations with continuous DCN measurements, and also to define the regions for suppressing the environment-light noise, so called background (BG).

Figure 2c is illustrating the $\mathrm{RCS}_{\text {raw }}$ shape before any DCN subtraction. The DCN signals shown in Fig.2b and the corrected ones presented in Fig.2d were smoothed by applying a filter (i.e. spatial-averaging) just for centering the attention on the main shape of the $\mathrm{RCS}_{\text {raw }}$ without all of these electrical fluctuations shown in Fig.2ac, but these smoothed profiles were never involved in the calculations. The first difference between black and gray profiles shown in Fig.2d is the minimization of the S-shape fluctuation and secondly the reduction/suppression of some near-range electronic fluctuations. After DCN correction, it can be noticed that the signal is noise cleaned up 
to $4 \mathrm{~km} \mathrm{agl}$, and the $\mathrm{S}$-shape oscillation of the $R C S_{\text {raw }}$ has been reduced. This S-shape of the Vaisala ceilometer signal is related to the opto-electronic system noises, but this analysis is beyond of the scope in this work.

\subsection{Background noise}

The second noise evaluated during the data pre-processing is the environmental light contamination of the ceilometer signal,which plays a role as a bias to the signal and it is well-known as background (BG) noise. This calculation was performed after DCN correction to have a signal with a significant reduction in the electronic fluctuations (i.e. minimization of the last kilometers oscillation). The BG is a constant value commonly consider as the mean value in the last kilometers of the lidar signals (i.e. 1 kilometer or more), but only if the signal present a constant noise. In our case, the signals were not so well behaved, unless that, we have reduced the oscillations considerably by suppressing DCN. As we shown in Fig.3, the BG presented a height-dependency from 7 to $15.4 \mathrm{~km}$ agl, therefore the following ranges of the profile were evaluated: BG1 (7-9 km agl), BG2 (9-11 km agl), BG3 (11-13 km agl) and BG4 (13-15.4km agl). One positive aspect observed on this height-dependency is that BG noise at each range presented a normal distribution (not shown here). Therefore, each range-dependent BG mean calculated for each profile is a good candidate to suppress the BG noise. Finally, we use the $\mathrm{BG}$ value that improved the dynamic range of the profiles (i.e. allows us to have positive signal in a far range), meaning that we systematically analyse each profile, then we performed the DCN correction and finally chose the best BG as it shown in Fig.3. Summarizing up, this procedure will enhance the probability of having good RCS profile to invert until $6 \mathrm{~km}$ agl, and it also improves the signal-to-noise ratio (SNR) in the medium/far range. The fact that ceilometers present a low SNR above $7 \mathrm{~km}$ agl suggest that only big events such as clouds and big aerosol plumes can be properly detected.

The signal retrieved from the Vaisala ceilometers presents a challenge to be pre-processed in order to retrieve aerosol optical properties. One of the main challenges is addressed in [16], where it was showed that most of Vaisala systems have a positive or negative signal distortion associated to electronic noise fluctuations. The correction of this fluctuation is tackled by suppressing cosmetic offsets ([16]) or dark corrections ([17]). In this work, the DCN measurement and also the search of the best BG value assure that 
signal noise level and shape is improved. The corrected signal is defined in the manuscript as follows

$$
R C S^{*}(R)=R C S_{\text {raw }}-[D C N+B G]
$$

where $R C S_{\text {raw }}$ is the raw range corrected signal, DCN is a $30 \mathrm{~min}$ averaged profile and BG is the mean value that fulfilled the criteria already explained.

In Fig. 3 is presented the whole scheme of the signal pre-processing, showing that good BG selection is not a trivial process for ceilometers. In the example case showed in the top of the panel of Fig.3ad, it is performed the pre-processing on $11^{\text {th }}$ October 2019 at 7 UTC and in the bottom of the panel (Fig.3e-h) at 10 UTC. In black dots it is represented the signal spatially- averaged each $500 \mathrm{~m}$ together with the standard deviation. This representation has two aims, in one hand to evidence the shape of the $\mathrm{RSC}_{\text {raw }}$ and how it improves after the DCN suppression for different profiles. It can be noticed after this correction that the oscillation of the averaged points is substantially reduced in the far and near range. On the other hand, we can notice in Fig. $3 \mathrm{~b}-\mathrm{f}$ that there is a remaining oscillating noise above $7 \mathrm{~km}$ agl, therefore is imperative to evaluate the height-dependency of BG noise. The Fig.3 shows that the ceilometer BG noise is changing from one measurement to another, therefore the application of a systematic BG correction must be considered to each profile separately and checking which $B G$ value improves the dynamic range. From the example case at 7 UTC, we use the BG4, while at 10 UTC the BG2 was the one that improved the signal. With this procedure, we are increasing the amount of signal available to invert.

\subsection{Water vapor correction}

As mentioned before, one of the CL51 drawbacks is the impact of the water vapor absorption on the laser emission line Previous works have demonstrated that this effect can be minimized. The water vapor correction method used in this paper is based on the one proposed by [18]. To perform this correction, absolute humidity and temperature profiles are used as input. In this paper, those profiles were measured from co-located MWR each 2 min from 0 to $10 \mathrm{~km}$ agl. These profiles were interpolated to the ceilometer vertical resolution. Regarding the temporal coincidence of the measurements, the temporal resolution of the ceilometer was degraded to the MWR. 

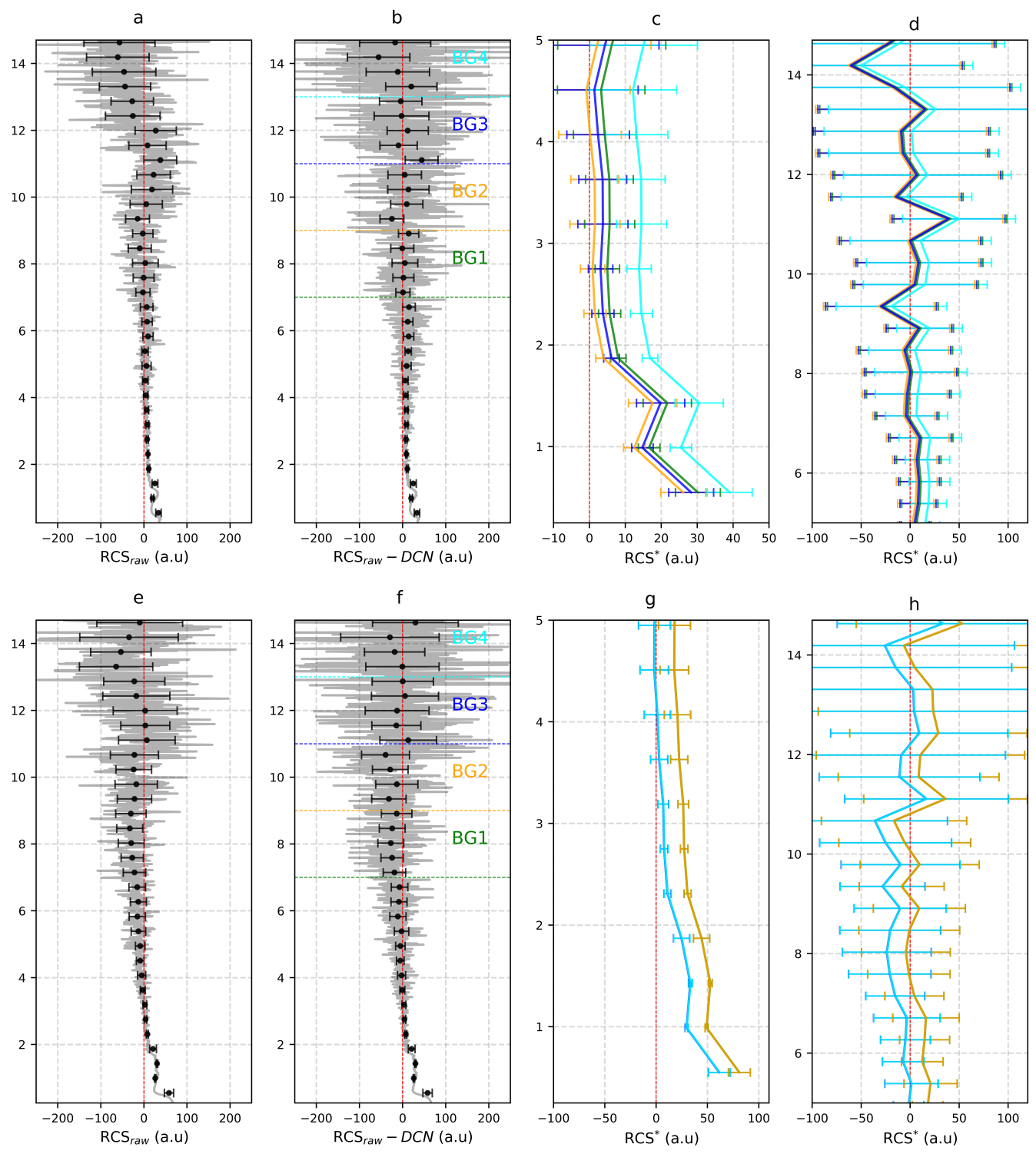

Figure 3: The figure presents the noise pre-processing applied to obtain the $\mathrm{RCS}_{*}=\mathrm{RSC}_{\text {raw }}$ (DC+BG). The measurements were took on $11^{\text {th }}$ October 2019. In the upper part are presented the results at 7 UTC and the bottom at 10UTC. The four BG ranges are shown. In green line is related to the correction for BG1, orange to BG2, blue

to BG3 and cyan to BG4. The standard deviation calculated corresponds to $500 \mathrm{~m}$-average in order to gain visibility at each step of the signal pre-processing. 
For the water vapor correction it is necessary to rewrite the transmittance term presented in Sec.2.2, splitting the transmittance term into the contributions of the molecules, particles and water vapor $\left(T_{m}^{2}, T_{p}^{2}, T_{w}^{2}\right)$. In this work, the transmittance term for molecules is calculated by using Rayleigh theory fed with atmospheric measurements (temperature and $\mathrm{RH}$ ) from the MWR. Transmittance from particles can be determined as a result of the crosschecking procedure during the Klett inversion explained below. $T_{w}^{2}$ can be defined as:

$$
T_{w}^{2}=\exp \left[-2 \int_{0}^{R} \alpha(r)_{w} \mathrm{~d} r\right]
$$

Where $\alpha(r)_{w}=\sigma(r)_{w} N(r)_{w}$, with $N(r)_{w}$ the water vapor number concentration and $\sigma(r)_{w}$ is the absorption cross section at the emitted wavelength. The $N(r)_{w}$ will be calculated from atmospheric measurements of absolute humidity profiles like $N(r)_{w}=7.25 \times 10^{22}$ AH $R_{w}$, where $R_{w}=0.462 \mathrm{Jg}^{-1} \mathrm{~K}^{-1}$. $\sigma(r)_{w}$ is calculated following the results presented on [18] for the absorption cross section simulated profiles. In this context, we consider a Gaussian shape of the ceilometer emission spectrum centered at $910 \mathrm{~nm}$ with $\Delta \lambda=3.5$ $\mathrm{nm}([18])$. As water vapor decrease with height, the Eq.3 is solved for the first $10 \mathrm{~km}$ of the atmosphere, but results are only shown until $3 \mathrm{~km}$ agl. The water vapor corrected profile is named hereafter as $R C S_{w}=R C S^{*}(R) / T_{w}^{2}$.

Figure 4 shows an example case where the water vapor correction is applied following the explained procedure. The atmospheric transmittance due to water vapor molecules is calculated using the profiles of temperature and AH from MWR, and from them calculate the $n_{w}$. In the example case shown in Fig.4b (red line), it is possible to evaluate the bias between $R C S^{*}$ and $R C S_{w}$, meaning that ceilometer signal tends to be overestimated if water vapor correction is not applied (Fig.4b, gray line). The larger differences between water vapor corrected and no-corrected profiles are within the first $1.5 \mathrm{~km}$ agl meanly because i) tropospheric water vapor molecules are more abundant at these altitudes, and ii) the MWR spatial resolution is better until $2 \mathrm{~km}$ agl. This increase of the overestimation is seen on the bias plot (Fig.4c), reaching almost 4 (a.u). The bias profile is highly noisy above 1.8 $\mathrm{km} \mathrm{agl} \mathrm{which} \mathrm{is} \mathrm{caused} \mathrm{by} \mathrm{the} \mathrm{increasing} \mathrm{of} \mathrm{the} R C S^{*}$ noise already discussed. 

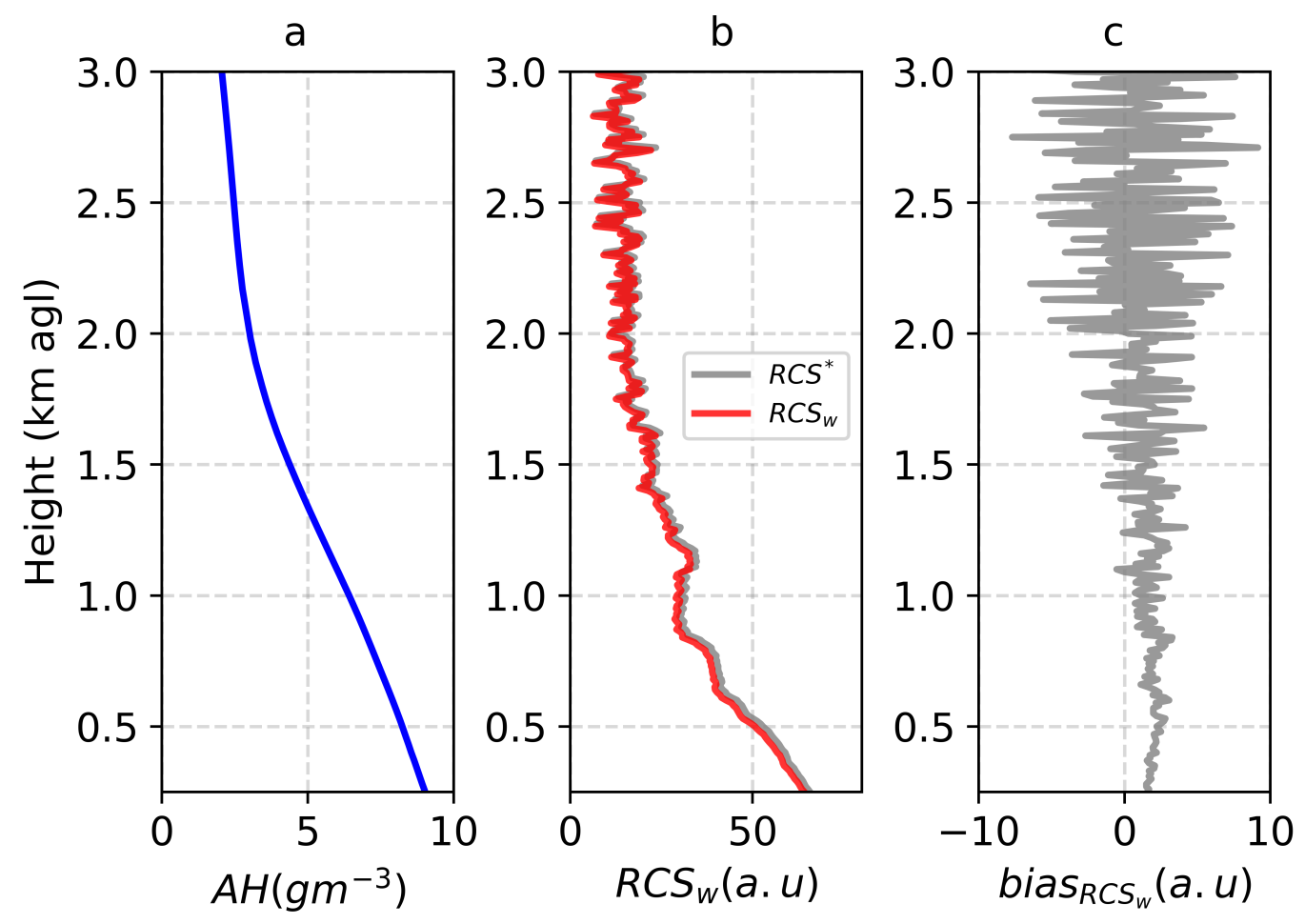

Figure 4: Water vapor correction corresponding to $11^{\text {th }}$ October 2019 at 06:00 UTC. a) Blue line represents the $\mathrm{AH}$ profile, b) $R C S_{w}$ with/without water vapor correction, red and gray line respectively are shown, and c) is the bias between $R C S^{*}$ and $R C S_{w}$ 


\section{Retrieval of aerosol profiles}

Ceilometer inversions have been successfully proved in Vaisala ceilometers in previous works $([17] ;[18])$. However one of the main challenges remain in the use of ancillary information from models for correcting the signal and then invert it. In this work, we propose an approach to tackle this problem by combining co-located atmospheric profiles measured next to the ceilometer and then applying a modified methodology of the semi-automatic lidar Klett inversion proposed in [12]. The aerosol retrieval method has been divided in 3 -step process as follows:

- Signal smoothing (Step 1): First the signal is noise-cleaned applying a $1 \mathrm{~h}$ average to the analyzed profiles. Then, in order to remove big peaks that remained from electronic noise, a spatial filter (40 m moving average filter) is applied. The aim of doing this filtering is to preserve the main shape of the $R C S_{w}$ with noise peak reduction.

- Rayleigh fit (Step 2): The Rayleigh fit procedure has been done by normalizing the signals, $\beta_{m}$ and $R C S_{w}$, in order to have comparable magnitudes. After this normalization, it is possible to check automatically the region where both signals have similar slopes by means of a linear fitting between 2 to $5 \mathrm{~km}$ agl. This altitude range is pre-set as an input to the algorithm in order to apply the slope's method, starting from $2 \mathrm{~km}$ agl; however, in turbulent days (where the Atmospheric Boundary Layer(ABL) is too high), the presence of aerosol may remain at those altitudes, for that reason, we consider a range until $5 \mathrm{~km}$ agl, assuring that the slopes will be checked for different atmospheric volumes (each $60 \mathrm{~m}$ ) until the fulfillment of the criteria. The criteria to consider that both slopes are close enough is based on the R-squared is the correlation coefficient (the Goodness-of-Fit of the linear regression), then when $r^{2}>0.7$ between normalized $\beta_{m}$ and $R C S_{w}$, and the percentual relative error between the slopes is below 0.2 , the Rayleigh zone is identified. Once that a layer containing the Rayleigh information has been found, just one reference point inside of it has to be selected. The iterative methodology to select this Rayleigh reference point is described below

- Backward Klett inversion (Step 3). 
The aerosol retrieval starts from the following lidar equation

$$
R C S_{w}(R)=C \beta(R) T_{m}^{2} T_{p}^{2}
$$

Then the backward Klett equation can be expressed as follows,

$$
\beta_{p}=\frac{A_{1}(R)}{A_{2}(R)}-\beta_{m}(R)
$$

where

$$
A_{1}(R)=R C S_{w}(R) \exp \left[2 \int_{r}^{r_{r e f}}\left(L R_{p}-L R_{m}\right) \beta_{m} d r\right]
$$

and

$$
A_{2}(R)=\frac{R C S_{w}(R)}{\beta\left(r_{r e f}\right)_{m}+\beta\left(r_{r e f}\right)_{p}}+2 \int_{r}^{r_{r e f}} L R(r)_{p} A_{1}(r) d r
$$

where $\beta_{m}$ is determined from Rayleigh theory using measured atmospheric profiles as inputs and the well-known molecular lidar ratio $\left(L R_{m}\right)$ from theory. The other terms like particle lidar ratio $\left(L R_{p}\right)$, and the reference height $\left(r_{r e f}\right)$ are calculated during the different steps involved in the modified [12] algorithm to Vaisala ceilometer.

An iterative Klett inversion process is performed for 240 values of $L R$ ranging from 35 to $150 \mathrm{Sr}$ each $0.5 \mathrm{sr}$, and for all possible height reference points inside Rayleigh zone found above, in order to retrieve $\beta_{p}$ and $\alpha_{p}$. The goal with this iterative process is to run Klett until find a combination of $L R$ and reference Rayleigh height that makes comparable the integrated $\alpha_{p}$ profile with the interpolated $A O D_{910}$ from sun photometer at the closest UTC time. The retrievals are considered as successful when the difference between integrated $\alpha_{p}$ profile and $A O D_{910}$ is lower than 0.001 .

The results are shown in Fig.5 for the case of $11^{\text {th }}$ October 2019 at ONERA site (occitanie Toulouse). The molecular profile (black dotted line in Fig.5a) is calculated using Rayleigh theory fed with temperature and RH profiles from MWR. The cases presented here had a normalization range from 
1.5 to $5 \mathrm{~km}$, assuring a region where Rayleigh and $R C S_{w}$ slopes are comparable. In Fig.5a the Rayleigh zone is detected from 1.8 to $3.5 \mathrm{~km}$ agl, and particularly in this example case a relative slope error of 0.05 with $r^{2}=0.9$ was found. The aim in the determination of the Rayleigh zone is to find the right altitude of reference to perform the backward Klett inversion, and as we see in Fig.5, due to the oscillations that remain in the $\mathrm{RCS}_{w}$, the algorithm may found a valid reference point in the far ranges within the zone selected (i.e. above $3 \mathrm{~km}$ agl as it is shown in the figure). For that reason $\alpha_{p}$ profiles are showing some variability in the proximity to the reference point(up to $\left.0.006 \mathrm{~km}^{-1}\right)$.

In order to assure the full overlap, it is used $250 \mathrm{~m}$ agl as the minimum height during the Klett inversion. The example case shown here presents the evolution of the inversions since early morning until afternoon. The dynamic of the atmosphere started with the aerosol relatively compressed below the ABL (below $0.8 \mathrm{~km} \mathrm{agl}$ ) due to the lack of solar radiation, but after 10 UTC the layers started to mix along the atmospheric column showing two aerosol accumulations, from 0.4 to $0.5 \mathrm{~km}$ agl and from 1.0 to $1.2 \mathrm{~km}$ agl. According to AERONET, along the day, we had the presence of mixed aerosols between urban and dust particles over Toulouse, predominating the coarse mode in the size distribution reaching $0.019 \mu \mathrm{m}^{3} / \mu \mathrm{m}^{2}$. The iterative Klett procedure for having $\beta_{p}$ profiles was performed by following the methodology, and then $\alpha_{p}$ profiles were obtained as it is shown in Fig.5b. During the morning, $\alpha_{p}$ was up to $0.03 \mathrm{~km}^{-1}$ in the first atmospheric layers (from 0.2 to $0.5 \mathrm{~km}$ agl), and then from 10 to 15 UTC $\alpha_{p}$ reached up $0.05 \mathrm{~km}^{-1}$ below the first $0.5 \mathrm{~km}$ agl. $\alpha_{p}=0.03 \mathrm{~km}^{-1}$ for the pronounced aerosol peaks from 12 to 15 UTC.

One of the pursued parameters on lidar inversion is the $L R$, in our case, over Toulouse area there is no previous information about this parameter, therefore as one of the main goals for the application of a semi-automatic Klett is to have in the near future a robust data base that will help us to understand better the aerosol behaviour over the region and also to have more tools for retrieving aerosol optical properties. Table1 presents the $L R$ obtained from Klett inversion, reporting an increasing $L R$ along the day ranging from 58.1 to $99.0 \mathrm{sr}$, with a positive correlation with the AOD increase. In the early morning, the $L R$ values are comparable with those reported in [12] and [17] for dust aerosols up to $60 \mathrm{Sr}$, but after $10 \mathrm{UTC}$ the $L R$ values obtained 

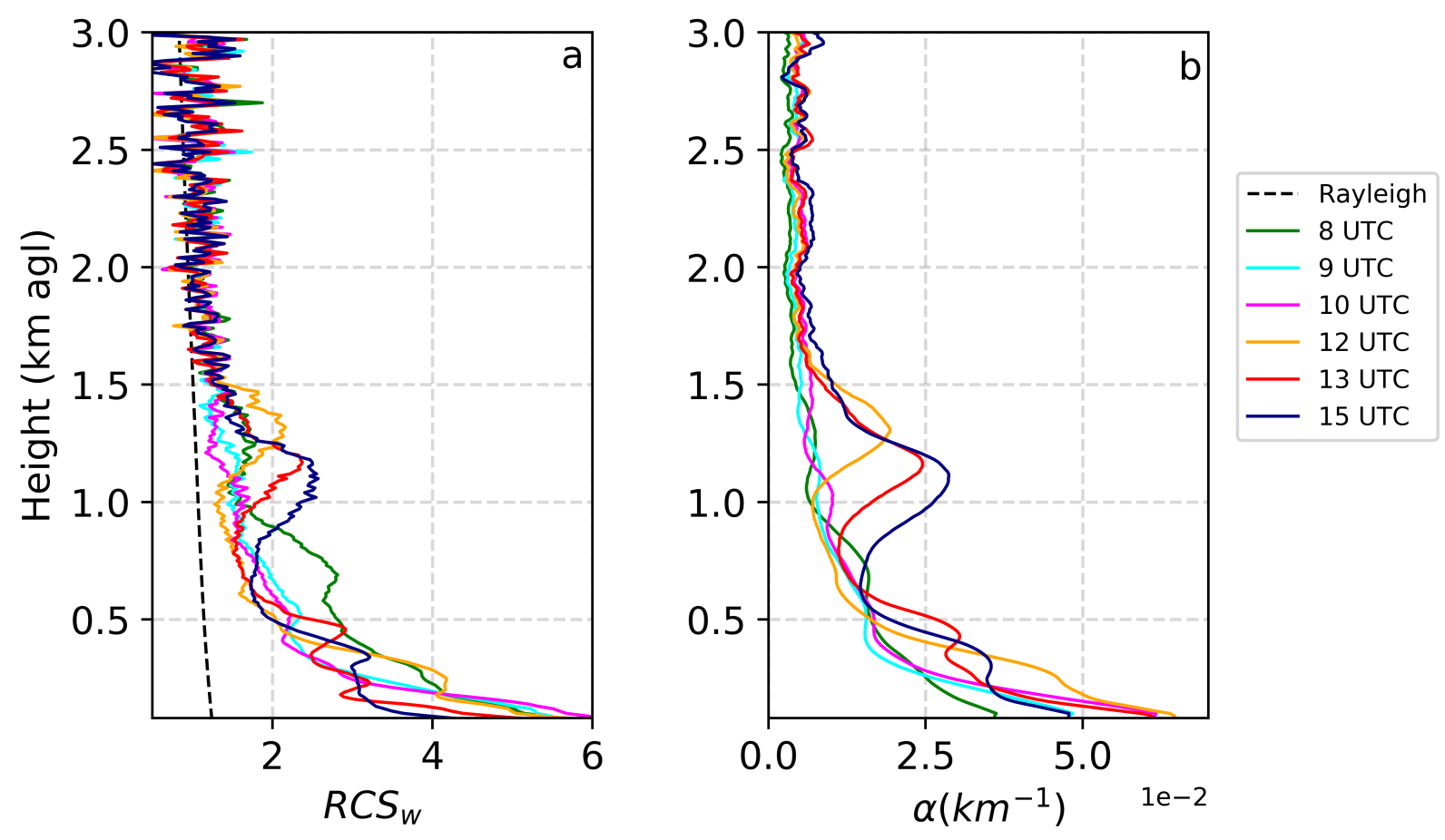

Figure 5: Example case of Klett inversion performed on $11^{\text {th }}$ October 2019 for the time-frames that sun photometer has $L R$ data availability. The $A O D_{910}$ was interpolated from AERONET data at the same UTC time of the 1h-averaged $R C S_{w}$. The black dotted line in a) refers to the Rayleigh fit profile and in colors are presented in a) the $R C S_{w}$ profiles used as input for the retrieval, while in b) is represented the $\alpha_{p}$ resulting from the inversion 
here increased up to $99 \mathrm{sr}$. In most of the studies, the $L R$ is imposed for the klett calculation because of the previous knowledge of the aerosol type, but in our case $L R$ is obtained from the continuous AOD cross-checking during the algorithm iterations, giving us the possibility to explore a wide range of $L R$ values that are related with different aerosol types.

Table 1: Klett inversions on $11^{\text {th }}$ October 2019.

\begin{tabular}{|c|c|c|}
\hline UTC & Klett AOD & Klett LR (sr) \\
\hline 8 & 0.039 & 72.2 \\
\hline 9 & 0.045 & 58.1 \\
\hline 10 & 0.052 & 68.7 \\
\hline 12 & 0.059 & 83.6 \\
\hline 13 & 0.060 & 99.0 \\
\hline 15 & 0.061 & 87.9 \\
\hline
\end{tabular}

The larger values found for LR with Klett inversion might be associated to the presence of the mixed aerosol (e.g. polluted dust), the physical separation between the sun photometer and the ceilometer, and also due to instrumental parameters that increase the uncertainties (e.g lidar constant). The inversions left two open paths for future works, from a technical sight will be the calculation of the ceilometer calibration constant along the seasons to considering different scenarios, and the design of the field campaigns for co-located measurements between ground base lidars and the ceilometer in order to inter-compare inversion products and improve the overlap information of the instrument. From a scientific point of view, we are studying the sensibility of the algorithm applied on synthetic lidar data and vaisala ceilometer signals in order to study the error propagation linked with the Rayleigh reference and LR values obtained along the iterations, and their impact over aerosol properties retrieved.

\section{Errors from water vapor uncertainties}

The methodology applied to retrieve aerosol profiles from vaisala CL51 ceilometer needs the a signal deep noise pre-processing and water vapor correction as we have shown in this work.Here, we have used atmospheric variables from the co-located MWR to improve the results, however, the water 
vapor correction in many stations with CL51 ceilometer is performed by taking atmospheric information from models, thus an extra uncertainty is added to the RCS and then propagated to the products retrieved. For that reason, we dedicate this section to quantify the errors when modelled inputs are considered instead of measured ones. The first part of this section is devoted to quantify the errors between atmospheric profiles calculated from HYSPLIT model instead of those measured with the MWR. In order to statistically characterize the errors between the model and MWR, we use the mean root mean square error (RMSE), and the mean bias error (MBE). These statistical quantities were calculated at each altitude in order to evaluate how far are the modelled data from the measured ones. The second part of this section is focused on the error quantification and its impact over the $R C S_{w}, \beta_{p}$ and $\alpha_{p}$ under both scenarios, assuming modelled data and measured ones. For doing that, the percentual relative error has been used (RE), where MWR quantities are considered as the reference.

\subsection{HYSPLIT vs MWR data}

In order to characterize the inversion calculation, a 2-step error estimation procedure is proposed (see Fig.1). In the first step, it was used a 2 months database (October-November 2019) from atmospheric measurements of temperature and $\mathrm{AH}$ from MWR, and modelled radiosondes retrieved using the GDAS meteorological database from HYSPLIT model. The aim is to estimate the root mean square error (RMSE) and mean bias error (MBE) between temperature, $\mathrm{AH}$ and $N(r)_{w}$ profiles assuming MWR as the reference, evaluating the error between model and MWR atmospheric data.

Figure 6 presents the result of the two-months error comparison between HYSPLIT modelled radiosondes retrieved at ONERA location using the GDAS meteorological database and the MWR profiles. The data were chosen assuring coincidence of the temporal and spatial resolutions between soundings and MWR profiles from 0 to $10 \mathrm{~km}$ agl. For the analysis, 488 coincident cases were found. Temperature and $\mathrm{AH}$, the main atmospheric variables involved in the pre-processing and inversion, were evaluated. $N_{w}$ was also analyzed but the RMSE and MBE errors were relatively lower and highly dependant of the temperature and AH errors. Figure 6a,b shows in red line the temperature profiles of RMSE and MBE calculations, pointing out that below $2 \mathrm{~km}$ agl the RMSE reach the lowest values (lower than $4^{\circ} \mathrm{C}$ ), 

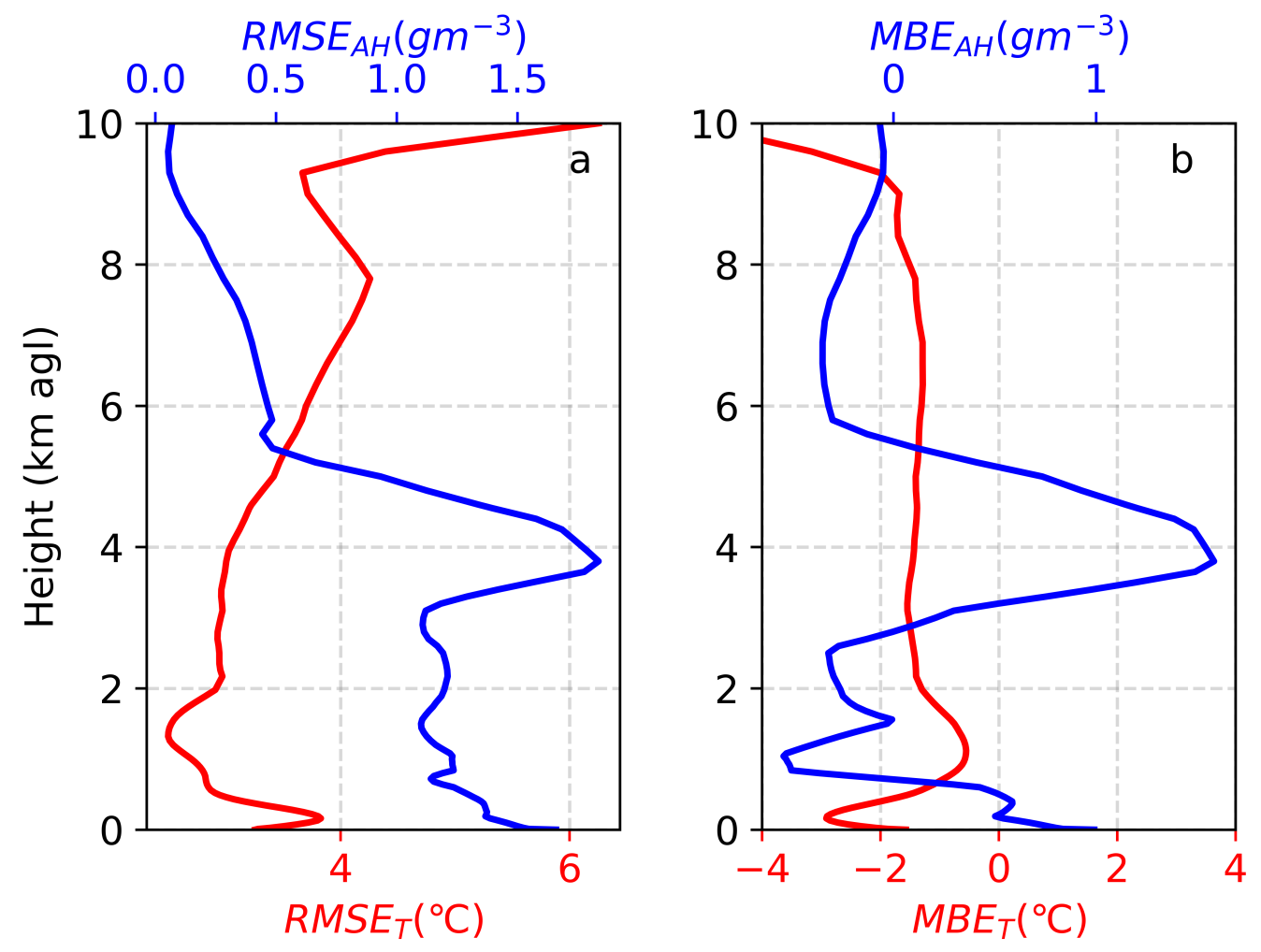

Figure 6: It is presented the error calculation in terms of RMSE and MBE, panel a) and b) respectively. For both panels, red line refers to temperature and blue line to AH. 
but after that altitude the RMSE increase monotonically until $6{ }^{\circ} \mathrm{C}$. Therefore assuming the MWR as the reference, the results indicate that modelled radiosondes can be far from the MWR measurements at least $4{ }^{\circ} \mathrm{C}$ in the crucial zone for ceilometer profiles. The Fig.6b shows that temperature retrieved profiles from HYSPLIT are always sub-estimating the MWR ones, being critical around the first hundred meters agl. For AH profiles (blue lines, Fig.6a,b), the RMSE shows values below $1.5 \mathrm{gm}^{-3}$ for the whole profile, however between 3.7 to $5.7 \mathrm{~km} \mathrm{agl}$, the RMSE presented a peak, which might be associated to the atmospheric region where the number of water vapor molecules decrease with height drastically as it was also seen in [17]. The MBE of the $\mathrm{AH}$ is quite variable, the ranges that overestimate the profile are from 0 to $200 \mathrm{~m}$ and $3 \mathrm{~km}$ to $5.8 \mathrm{~km}$ agl and the sub estimation ranges are from $1 \mathrm{~km}$ to $2.3 \mathrm{~km}$ and from $5.8 \mathrm{~km}$ to the end.

\subsection{Uncertainty propagation on aerosol profiles}

The second part of the error calculation is performed just to six particular cases where lidar inversion was applied. In the last section, it was seen the performance of the atmospheric variables between measured and modelled data, but here we centered our attention in determining the error propagation in terms of the percentual relative error (RE) for temperature, $\mathrm{AH}, \mathrm{RCS}_{w}, \beta_{p}$ and $\alpha_{p}$ in order to evaluate the error propagation during inversion process considering modelled data instead of atmospheric measurements.

In Fig.7 are presented the errors of the input measurements used for retrieving $\beta_{p}$ and $\alpha_{p}$ applying the Klett inversion already discussed. In Fig.7a is reported the percentual RE between temperature and $\mathrm{AH}$ profiles considering MWR as reference, from there it can be seen that RE in temperature (red line) are higher in the first $800 \mathrm{~m}$ agl (up to $5 \%$ ), but then, the RE do not surpasses $1 \%$. Meanwhile, AH presented higher RE. AH relative errors (blue line) below $2 \mathrm{~km}$ agl were lower than $20 \%$, but above $2 \mathrm{~km}$ agl the errors can reach $100 \%$ faster. The absolute errors on $N_{w}$ at using the model or the MWR data are really lower, practically negligible (not shown here).

Figure7b shows the RE on the $R C S_{w}$ profile for the same example case presented in Sec.4. Therefore, the results of having up to $1 \% \mathrm{RE}$ in temperature and close to $20 \%$ in $\mathrm{AH}$ are causing an increase in the $R C S_{w} \mathrm{RE}$ up to $30 \%$ below $2 \mathrm{~km}$ agl, and above this height the absolute error increase drastically reaching up more than $100 \%$ above $3.5 \mathrm{~km}$ agl. The evaluation 

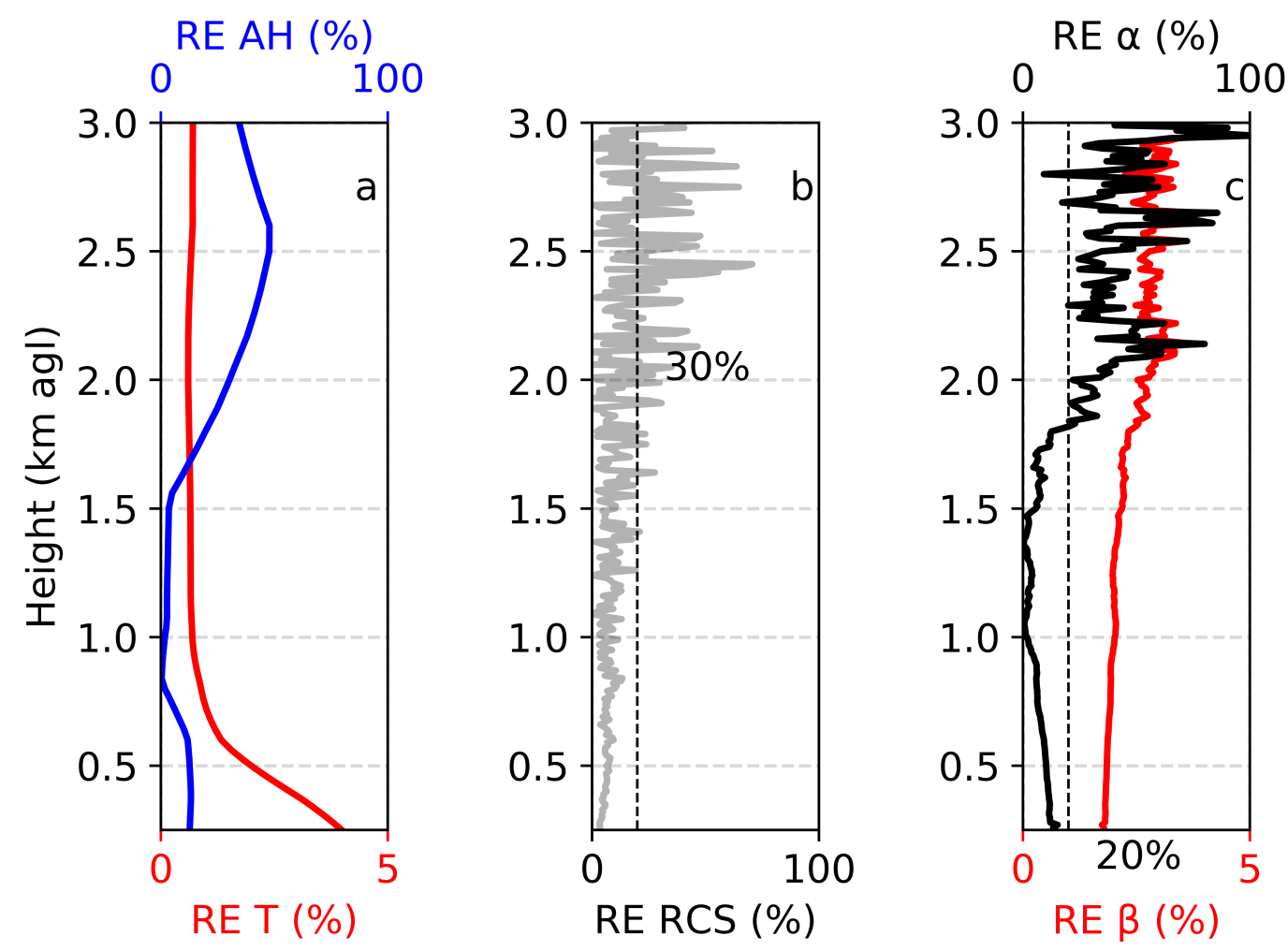

Figure 7: The panel presents the different steps in the example case on $11^{\text {th }}$ October 2019 at 8 UTC for evaluation the relative error (RE) in the inversion process. a) In red lines is represented the temperature and blue line refers to $\mathrm{AH}, \mathrm{b}$ ) is the error committed in the $R C S_{w}$ signal, and c) $\mathrm{RE}$ of the $\beta_{p}$ (red line), and $\alpha_{p}$ (black line)

of this error in the Klett inversion is presented in Fig.7c (red line for $\beta_{p}$ and black line for $\alpha_{p}$ ), where RE in the first $2 \mathrm{~km}$ agl reached up to $3 \%$ in $\beta_{p}$, and up to $20 \%$ in $\alpha_{p}$. The errors in the $R C S_{w}$ profile due to the use of modelled data instead of measured are showing that it is imperative the use of accurate atmospheric profiles for improve the main vaisala product. Additionally, the $\mathrm{RE}$ found here for $R C S_{w}$ have to be added to the high noise of this product, which in fact leads to increase the error peaks shown in Fig.7b

Table2 reports the mean values of the $\mathrm{RE}$ in percentage for six cases evaluated during the two-months study. The cases 1,2,3 were retrieved on $11^{\text {th }}$ October 2019 at 06:00, 09:00, and 12:00 UTC, case 4 to $20^{\text {th }}$ November 
Table 2: Mean RE calculated for six inversion cases using the semi-automatic Klett method. The variables evaluated were Temperature, $\mathrm{AH}, R C S_{w}, \beta_{p}$ and $\alpha_{p}$. The study cases $1,2,3$ were measured on $11^{\text {th }}$ October 2019 at $6 \mathrm{~h}, 9 \mathrm{~h}$, and $12 \mathrm{~h}$ respectively, case 4 on $20^{\text {th }}$ November 2019 at $6 \mathrm{~h}$ and cases 5 and 6 on $21^{\text {st }}$ November 2019 at $9 \mathrm{~h}$ and $12 \mathrm{~h}$. The mean values are calculated for five different atmospheric volumes: from 0 to $0.5 \mathrm{~km}$ agl, from 0.5 to $1 \mathrm{~km}$ agl, from 1 to $2 \mathrm{~km} \mathrm{agl}$

\begin{tabular}{|c|c|c|c|c|}
\hline & & 0 to $0.5 \mathrm{~km}$ agl & 0.5 to $1 \mathrm{~km} \mathrm{agl}$ & 1 to $2 \mathrm{~km}$ agl \\
\hline \multirow[t]{6}{*}{$\mathbf{T}(\%)$} & Case 1 & $1,8 \pm 0,9$ & $0,1 \pm 0,1$ & $0,70 \pm 0,08$ \\
\hline & Case 2 & $3,9 \pm 0,7$ & $1,1 \pm 0,3$ & $0,65 \pm 0,02$ \\
\hline & Case 3 & $3,4 \pm 0,4$ & $2,5 \pm 0,4$ & $1,3 \pm 0,2$ \\
\hline & Case 4 & $1,5 \pm 0,5$ & $0,14 \pm 0,08$ & $0,5 \pm 0,3$ \\
\hline & Case 5 & $2,1 \pm 0,7$ & $0,3 \pm 0,1$ & $0,6 \pm 0,2$ \\
\hline & Case 6 & $2,0 \pm 0,4$ & $1,4 \pm 0,3$ & $0,88 \pm 0,05$ \\
\hline \multirow[t]{6}{*}{$\mathbf{A H}(\%)$} & Case 1 & $10 \pm 1$ & $5 \pm 3$ & $12 \pm 9$ \\
\hline & Case 2 & $13,4 \pm 0,9$ & $6 \pm 5$ & $7 \pm 7$ \\
\hline & Case 3 & $16,5 \pm 0,7$ & $11 \pm 4$ & $6 \pm 4$ \\
\hline & Case 4 & $3 \pm 1$ & $6 \pm 4$ & $25 \pm 13$ \\
\hline & Case 5 & $3 \pm 1$ & $18 \pm 9$ & $53 \pm 17$ \\
\hline & Case 6 & $3 \pm 2$ & $20 \pm 9$ & $55 \pm 17$ \\
\hline \multirow[t]{6}{*}{$R C S_{w}(\%)$} & Case 1 & $4 \pm 10$ & $5 \pm 2$ & $8 \pm 6$ \\
\hline & Case 2 & $5 \pm 9$ & $5 \pm 2$ & $8 \pm 6$ \\
\hline & Case 3 & $5 \pm 5$ & $5 \pm 2$ & $9 \pm 7$ \\
\hline & Case 4 & $2 \pm 3$ & $5 \pm 3$ & $7 \pm 6$ \\
\hline & Case 5 & $3 \pm 4$ & $3 \pm 2$ & $7 \pm 6$ \\
\hline & Case 6 & $5 \pm 9$ & $3 \pm 2$ & $8 \pm 7$ \\
\hline \multirow[t]{6}{*}{$\beta_{p}(\%)$} & Case 1 & $1,81 \pm 0,02$ & $1,92 \pm 0,04$ & $2,2 \pm 0,3$ \\
\hline & Case 2 & $1,77 \pm 0,03$ & $1,69 \pm 0,02$ & $1,62 \pm 0,04$ \\
\hline & Case 3 & $1,67 \pm 0,01$ & $1,18 \pm 0,02$ & $1,18 \pm 0,05$ \\
\hline & Case 4 & $0,85 \pm 0,02$ & $0,88 \pm 0,03$ & $0,46 \pm 0,08$ \\
\hline & Case 5 & $1,26 \pm 0,02$ & $1,23 \pm 0,07$ & $1,1 \pm 0,2$ \\
\hline & Case 6 & $0,96 \pm 0,02$ & $0,7 \pm 0,2$ & $0,20 \pm 0,07$ \\
\hline \multirow[t]{6}{*}{$\alpha_{p}(\%)$} & Case 1 & $12 \pm 1$ & $7 \pm 2$ & $10 \pm 11$ \\
\hline & Case 2 & $5 \pm 1$ & $0,7 \pm 0,6$ & $4 \pm 2$ \\
\hline & Case 3 & $1,5 \pm 0,7$ & $2 \pm 1$ & $3 \pm 2$ \\
\hline & Case 4 & $3 \pm 2$ & $7 \pm 3$ & $44 \pm 10$ \\
\hline & Case 5 & $1,3 \pm 0,8$ & $4 \pm 4$ & $18 \pm 10$ \\
\hline & Case 6 & $26 \pm 3$ & $25 \pm 20$ & $73 \pm 9$ \\
\hline
\end{tabular}


2019 at 06:00 UTC and cases 5 and 6 to $21^{\text {st }}$ November 2019 at 09:00 and 12:00 UTC. The averages were calculated for 3 different layers for center the attention in the aerosol products: from 0 to $0.5 \mathrm{~km}$ agl, from 0.5 to $1 \mathrm{~km}$ agl, from 1 to $2 \mathrm{~km}$ agl. The inversion products $\left(\beta_{p}\right.$ and $\left.\alpha_{p}\right)$ were analyzed until $2 \mathrm{~km}$ agl.

Table2 shows that mean temperature RE were always below $4 \%$ with lower standard deviation (SD). However, in the first $0.5 \mathrm{~km}$ agl case 2 and 3 presented mean values up to $4 \%$. On the contrary, AH presented higher mean error values mainly above $3 \mathrm{~km}$ agl as it was expected from the analysis performed in the previous section with mean errors higher than $40 \%$ (not shown here). Centering the attention in the first two kilometres of the atmosphere, the errors in $\mathrm{AH}$ were below $30 \%$, except for case 5,6 with mean errors up to $55 \%$. As it was seen on Sec.3, the AH is deeply linked with the transmittance term at correcting the $R C S^{*}$ signal, therefore the relatively large differences in $\mathrm{AH}$ profiles are contributing to $R C S_{w}$ profiles. According to our results, mean RE up to $30 \%$ in $\mathrm{AH}$ might cause errors in $R C S_{w}$ that reach $10 \%$ in the first $2 \mathrm{~km}$ agl, and like the amount of water vapor is highly variable in the first two kilometers of the atmosphere, nearly-real measurements of AH will improve the ceilometer signal significantly, otherwise calculations without using real ambient measurements might lead to considerable error increase.

The retrieved products $\beta_{p}$ and $\alpha_{p}$ have a RE that is influenced firstly by the input profiles which are Rayleigh and $R C S_{w}$ (including the noises remained), and secondly the accurate atmospheric reference to start the backward inversion, which is linked with the sunphotometric data for setting the correct LR, among other errors associated to the algorithm calculation itself. From Table2, it is possible to see that in general, the mean RE is lower than $3 \%$ below $2 \mathrm{~km}$ agl for $\beta_{p}$, meanwhile the errors in $\alpha_{p}$ can reach $25 \%$ within this height. Some mean errors for $\alpha_{p}$ in cases 4,5,6 are quite larger than other cases, and this might be linked with the relative elevated AH errors (see on Table2). Considering this error propagation in $\alpha_{p}$, we found that without using co-located atmospheric measurements, this inversion product can be also estimated but considering an addition up to $25 \%$ of RE for Vaisala CL51 ceilometers, avoiding those cases where AH RE was extremely high. The slight increase in the standard deviation errors reported for the $R C S_{w}$ in the last air volume evaluated from 1 to $2 \mathrm{~km}$ agl (Table2) are associated to the 
increase of the noise that we already discussed in the pre-processing section, linked with the quality of the ceilometer signals and also in Fig.7b where the $\mathrm{RE}$ of the $R C S_{w}$ increased considerably faster with height, pointing out that aerosol inversion with ceilometers above $3 \mathrm{~km}$ agl might lead to larger errors.

\section{6. conclusions}

The purpose of this work is to continue tackling the central problems that Vaisala CL51 ceilometers have for improving aerosol inversion products. Firstly, the ceilometer pre-processing is discussed by taking advantage of the termination hood external tool. Between day and night the instrument presented only small differences in terms of shape and noise levels of DCN signals detected, therefore we decided to work with 30 min-averaged nighttime DCN profiles. For the BG analysis, we used a systematic selection of the best height-dependence $\mathrm{BG}$, avoiding that $R C S^{*}$ goes to negative values within the first $5 \mathrm{~km}$ agl. After suppressing DCN and BG, the signal remained positive for more than $5 \mathrm{~km}$ agl and S-shape oscillations were minimized.

The methodology designed involved the water vapor correction by using a co-located MWR for measuring atmospheric variables. This synergy allowed us to improve the quality of the signal by calculating the water vapor transmission term of the lidar equation using measurements of temperature and $\mathrm{AH}$, and deriving from them the $N_{w}$. For the inversion, Rayleigh profiles were calculated using MWR measurements and the $R C S_{w}$ profiles.In addition, the sun photometer AOD time series were interpolated to $910 \mathrm{~nm}$ in order to compare the results with those obtained from the integrated $\alpha$ profiles retrieved after Klett's inversion procedure. For the iterative Klett inversion method, a minimum difference between $\mathrm{AOD}_{910}$ and integrated $\alpha$ profiles lower than $\leqslant 0.001$ was set as the condition to constrain the aerosol amount along the iterations.

An error propagation was performed applying the methodology under two scenarios, considering i) modelled atmospheric data and ii) atmospheric measurements. The error estimation was performed first by means of the RMSE and MBE estimators calculated for two-months of temperature and AH modelled HYSPLIT radiosondes and MWR. The aim was to quantify the error propagation on the two atmospheric variables involved in the $R C S_{w}$ 
correction. The errors were calculated for 488 samples covering different atmospheric scenarios, showing that for temperatures below $2 \mathrm{~km}$ agl the RMSE is lower than $4{ }^{\circ} \mathrm{C}$, and above is up to $6{ }^{\circ} \mathrm{C}$, whereas $\mathrm{AH}$ presented an error up to $2 \mathrm{gm}^{-3}$, which in terms of water vapor correction is significant. The MBE shown that temperature modelled profiles were always underestimating MWR ones (up to $-1{ }^{\circ} \mathrm{C}$ ), and $\mathrm{AH}$ MBE was high variable, underestimating the MWR measures from $1 \mathrm{~km}$ to $2.3 \mathrm{~km}$ agl and from $5.8 \mathrm{~km}$ agl to the end of the profile (reaching up $-0.5 \mathrm{gm}^{-3}$ ) and the overestimation reached up 1.5 $\mathrm{gm}^{-3}$ from ground to $0.2 \mathrm{~km}$ agl and from $3 \mathrm{~km}$ to $5.8 \mathrm{~km}$ agl.

In summary, we found that the use of modelled data instead atmospheric measurements is primarily influencing the $R C S_{w}$, and then the inversion products obtained from the ceilometer. As a result of that, the percentual relative error estimation within the critical zone for aerosol inversion (first $2 \mathrm{~km}$ agl), the temperature presented errors below $4 \%$, while in the first $2 \mathrm{~km}$ agl AH were below $25 \%$. These errors affected the $R C S_{w}$ signal driving to an error up to $9 \%$ in the first $2 \mathrm{~km}$ agl. The errors propagated on $\beta_{p}$ during Klett calculation were lower than $2.2 \%$, leading to an error in $\alpha_{p}$ up to 25 $\%$. Therefore, one can conclude that the use of atmospheric modelled data instead of measurements for water vapor correction on vaisala CL51 ceilometers will lead large errors on inversion products i.e. $\alpha_{p}$.

Finally, the Klett algorithm could be improved by determining the calibration constant of the instrument tackling one of the E-PROFILE objectives. This work can be developed in further studies by having a larger ceilometer database for making a seasonal analysis of the calibration constant as function of the internal temperature in a semi-automatic way at ONERA site. In addition, the knowledge of the full overlap height of the system could also help us to improve the inversion products, therefore a further measurement campaign with ground based lidar operating co-located to the ceilometer might be an ideal solution to have the ceilometer fully characterized.

\section{References}

[1] O. Boucher, D. Randall, P. Artaxo, C. Bretherton, G. Feingold, P. Forster, V.-M. Kerminen, Y. Kondo, H. Liao, U. Lohmann, P. Rasch, S. K. Satheesh, S. Sherwood, B. Stevens, X. Y. Zhang, Clouds and 
aerosols, Cambridge University Press, Cambridge, UK, 2013, pp. 571657. doi:10.1017/CBO9781107415324.016.

[2] A. Chaikovsky, O. Dubovik, B. Holben, A. Bril, P. Goloub, D. Tanré, G. Pappalardo, U. Wandinger, L. Chaikovskaya, S. Denisov, J. Grudo, A. Lopatin, Y. Karol, T. Lapyonok, V. Amiridis, A. Ansmann, A. Apituley, L. Allados-Arboledas, I. Binietoglou, A. Boselli, G. D'Amico, V. Freudenthaler, D. Giles, M. J. Granados-Muñoz, P. Kokkalis, D. Nicolae, S. Oshchepkov, A. Papayannis, M. R. Perrone, A. Pietruczuk, F. Rocadenbosch, M. Sicard, I. Slutsker, C. Talianu, F. DeÂA Tomasi, A. Tsekeri, J. Wagner, X. Wang, Lidar-radiometer inversion code (liric) for the retrieval of vertical aerosol properties from combined lidar/radiometer data: development and distribution in earlinet, Atmospheric Measurement Techniques 9 (2016) 1181-1205. URL: https : //www . atmos-meas-tech.net/9/1181/2016/. doi:10.5194/amt9-1181-2016.

[3] A. Lopatin, O. Dubovik, A. Chaikovsky, P. Goloub, T. Lapyonok, D. Tanré, P. Litvinov, Enhancement of aerosol characterization using synergy of lidar and sun-photometer coincident observations: the garrlic algorithm, Atmospheric Measurement Techniques 6 (2013) 2065-2088. URL: https : //www . atmos-meas-tech.net/6/2065/2013/. doi:10.5194/amt-6-2065-2013.

[4] J. A. Benavent-Oltra, R. Román, M. J. Granados-Muñoz, D. Pérez-Ramírez, P. Ortiz-Amezcua, C. Denjean, A. Lopatin, H. Lyamani, B. Torres, J. L. Guerrero-Rascado, D. Fuertes, O. Dubovik, A. Chaikovsky, F. J. Olmo, M. Mallet, L. AladosArboledas, Comparative assessment of grasp algorithm for a dust event over granada (spain) during charmex-adrimed 2013 campaign, Atmospheric Measurement Techniques 10 (2017) 44394457. URL: https://www. atmos-meas-tech.net/10/4439/2017/. doi:10.5194/amt-10-4439-2017.

[5] J. A. Benavent-Oltra, R. Román, J. A. Casquero-Vera, D. PérezRamírez, H. Lyamani, P. Ortiz-Amezcua, A. E. Bedoya-Velásquez, G. de Arruda Moreira, A. Barreto, A. Lopatin, D. Fuertes, M. Herrera, B. Torres, O. Dubovik, J. L. Guerrero-Rascado, P. Goloub, F. J. Olmo-Reyes, L. Alados-Arboledas, Different strategies to 
retrieve aerosol properties at night-time with the grasp algorithm, Atmospheric Chemistry and Physics 19 (2019) 1414914171. URL: https://www . atmos-chem-phys. net/19/14149/2019/. doi:10.5194/acp-19-14149-2019.

[6] A. E. Bedoya-Velásquez, F. Navas-Guzmán, M. J. Granados-Muñoz, G. Titos, R. Román, J. A. Casquero-Vera, P. Ortiz-Amezcua, J. A. Benavent-Oltra, G. de Arruda Moreira, E. Montilla-Rosero, C. D. Hoyos, B. Artiñano, E. Coz, F. J. Olmo-Reyes, L. Alados-Arboledas, J. L. Guerrero-Rascado, Hygroscopic growth study in the framework of earlinet during the slope i campaign: synergy of remote sensing and in situ instrumentation, Atmospheric Chemistry and Physics 18 (2018) 70017017. URL: https://www . atmos-chem-phys.net/18/7001/2018/. doi:10.5194/acp-18-7001-2018.

[7] G. de Arruda Moreira, J. L. Guerrero-Rascado, J. A. BenaventOltra, P. Ortiz-Amezcua, R. Román, A. E. Bedoya-Velásquez, J. A. Bravo-Aranda, F. J. Olmo Reyes, E. Landulfo, L. Alados-Arboledas, Analyzing the turbulent planetary boundary layer by remote sensing systems: the doppler wind lidar, aerosol elastic lidar and microwave radiometer, Atmospheric Chemistry and Physics 19 (2019) 12631280. URL: https://www . atmos-chem-phys.net/19/1263/2019/. doi:10.5194/acp-19-1263-2019.

[8] A. E. Bedoya-Velásquez, G. Titos, J. A. Bravo-Aranda, M. Haeffelin, O. Favez, J.-E. Petit, J. A. Casquero-Vera, F. J. Olmo-Reyes, E. Montilla-Rosero, C. D. Hoyos, L. Alados-Arboledas, J. L. GuerreroRascado, Long-term aerosol optical hygroscopicity study at the actris sirta observatory: synergy between ceilometer and in situ measurements, Atmospheric Chemistry and Physics 19 (2019) 78837896. URL: https://www . atmos-chem-phys.net/19/7883/2019/. doi:10.5194/acp-19-7883-2019.

[9] M. Haeffelin, Q. Laffineur, J.-A. Bravo-Aranda, M.-A. Drouin, J.A. Casquero-Vera, J.-C. Dupont, H. De Backer, Radiation fog formation alerts using attenuated backscatter power from automatic lidars and ceilometers, Atmospheric Measurement Techniques 9 (2016) 5347-5365. URL: https://www . atmos-meas-tech . net/9/5347/2016/. doi:10.5194/amt-9-5347-2016. 
[10] M. Wiegner, F. Madonna, I. Binietoglou, R. Forkel, J. Gasteiger, A. Geiß, G. Pappalardo, K. Schäfer, W. Thomas, What is the benefit of ceilometers for aerosol remote sensing? an answer from earlinet, Atmospheric Measurement Techniques 7 (2014) 1979-1997. URL: https://www . atmos-meas-tech.net/7/1979/2014/. doi:10.5194/amt7-1979-2014.

[11] Y. Jin, K. Kai, K. Kawai, T. Nagai, T. Sakai, A. Yamazaki, A. Uchiyama, D. Batdorj, N. Sugimoto, T. Nishizawa, Ceilometer calibration for retrieval of aerosol optical properties, Journal of Quantitative Spectroscopy and Radiative Transfer 153 (2015) 49 - 56. URL: http://www.sciencedirect.com/science/article/pii/S0022407314004257. doi:https://doi.org/10.1016/j.jqsrt.2014.10.009, topical issue on optical particle characterization and remote sensing of the atmosphere: Part II.

[12] A. Cazorla, J. A. Casquero-Vera, R. Román, J. L. Guerrero-Rascado, C. Toledano, V. E. Cachorro, J. A. G. Orza, M. L. Cancillo, A. Serrano, G. Titos, M. Pandolfi, A. Alastuey, N. Hanrieder, L. Alados-Arboledas, Near-real-time processing of a ceilometer network assisted with sunphotometer data: monitoring a dust outbreak

over the iberian peninsula, Atmospheric Chemistry and Physics 17 (2017) 11861-11876. URL: https://www . atmos-chem-phys . net/17/11861/2017/. doi:10.5194/acp-17-11861-2017.

[13] R. Román, J. Benavent-Oltra, J. Casquero-Vera, A. Lopatin, A. Cazorla, H. Lyamani, C. Denjean, D. Fuertes, D. Pérez-Ramírez, B. Torres, C. Toledano, O. Dubovik, V. Cachorro, A. [de Frutos], F. Olmo, L. Alados-Arboledas, Retrieval of aerosol profiles combining sunphotometer and ceilometer measurements in grasp code, Atmospheric Research 204 (2018) 161 - 177. URL: http://www.sciencedirect.com/science/article/pii/S0169809517312577. doi:https://doi.org/10.1016/j.atmosres.2018.01.021.

[14] M. Herreras, R. Román, A. Cazorla, C. Toledano, H. Lyamani, B. Torres, V. Cachorro, F. Olmo, L. Alados-Arboledas, A. de Frutos, Evaluation of retrieved aerosol extinction profiles using 
as reference the aerosol optical depth differences between various heights, Atmospheric Research 230 (2019) 104625. URL: https://www.sciencedirect.com/science/article/pii/S0169809519300432. doi:10.1016/j.atmosres.2019.1046259.

[15] G. Titos, M. Ealo, R. Román, A. Cazorla, Y. Sola, O. Dubovik, A. Alastuey, M. Pandolfi, Retrieval of aerosol properties from ceilometer and photometer measurements: long-term evaluation with in situ data and statistical analysis at montsec (southern pyrenees), Atmospheric Measurement Techniques 12 (2019) 32553267. URL: https://www. atmos-meas-tech.net/12/3255/2019/. doi:10.5194/amt-12-3255-2019.

[16] S. Kotthaus, E. O'Connor, C. Münkel, C. Charlton-Perez, M. Haeffelin, A. M. Gabey, C. S. B. Grimmond, Recommendations for processing atmospheric attenuated backscatter profiles from vaisala cl31 ceilometers, Atmospheric Measurement Techniques 9 (2016) 3769-3791. URL: https : //www . atmos-meas-tech . net/9/3769/2016/. doi:10.5194/amt9-3769-2016.

[17] C. R. Marcos, J. L. Gómez-Amo, C. Peris, R. Pedrós, M. P. Utrillas, J. A. Martínez-Lozano, Analysis of four years of ceilometerderived aerosol backscatter profiles in a coastal site of the western mediterranean, Atmospheric Research 213 (2018) 331 - 345. URL: http://www.sciencedirect.com/science/article/pii/S016980951830468X. doi:https://doi.org/10.1016/j.atmosres.2018.06.016.

[18] M. Wiegner, J. Gasteiger, Correction of water vapor absorption for aerosol remote sensing with ceilometers, Atmospheric Measurement Techniques 8 (2015) 3971-3984. URL: https ://www . atmos-meas-tech.net/8/3971/2015/. doi:10.5194/amt8-3971-2015.

[19] J. D. Klett, Lidar inversion with variable backscatter/extinction ratios, Appl. Opt. 24 (1985) 1638-1643. URL: $\quad$ http://ao.osa.org/abstract. cfm?URI=ao-24-11-1638. doi:10.1364/AO.24.001638.

[20] J. D. Klett, Stable analytical inversion solution for processing lidar returns, Appl. Opt. 20 (1981) 211-220. 
URL: $\quad$ http: //ao.osa.org/abstract. cfm?URI=ao-20-2-211. doi:10.1364/AO.20.000211.

[21] T. Rose, S. Crewell, U. Löhnert, C. Simmer, A network suitable microwave radiometer for operational monitoring of the cloudy atmosphere, Atmospheric Research 75 (2005) 183 - 200. URL: http://www.sciencedirect.com/science/article/pii/S0169809505000189. doi:https://doi.org/10.1016/j.atmosres.2004.12.005, cLIWA-NET: Observation and Modelling of Liquid Water Clouds.

[22] A. E. Bedoya-Velásquez, F. Navas-Guzmán, G. de Arruda Moreira, R. Román, A. Cazorla, P. Ortiz-Amezcua, J. A. Benavent-Oltra, L. Alados-Arboledas, F. J. Olmo-Reyes, I. Foyo-Moreno, E. MontillaRosero, C. D. Hoyos, J. L. Guerrero-Rascado, Seasonal analysis of the atmosphere during five years by using microwave radiometry over a mid-latitude site, Atmospheric Research 218 (2019) 78 - 89. URL: http://www.sciencedirect.com/science/article/pii/S0169809518312857. doi:https://doi.org/10.1016/j.atmosres.2018.11.014.

[23] B. Holben, T. Eck, I. Slutsker, D. Tanré, J. Buis, A. Setzer, E. Vermote, J. Reagan, Y. Kaufman, T. Nakajima, F. Lavenu, I. Jankowiak, A. Smirnov, Aeronet-a federated instrument network and data archive for aerosol characterization, Remote Sensing of Environment 66 (1998) 1 - 16. URL: http://www.sciencedirect. com/science/article/pii/S0034425798000315. doi:https://doi.org/10.1016/S0034-4257(98)00031-5.

[24] O. Dubovik, M. D. King, A flexible inversion algorithm for retrieval of aerosol optical properties from sun and sky radiance measurements, Journal of Geophysical Research: Atmospheres 105 (2000) 20673-20696. URL: https : //agupubs . onlinelibrary . wiley.com/doi/abs/10 . 1029/2000JD900282. doi:10.1029/2000JD900282.

[25] O. Dubovik, B. Holben, T. F. Eck, A. Smirnov, Y. J. Kaufman, M. D. King, D. Tanré, I. Slutsker, Variability of absorption and optical properties of key aerosol types observed in worldwide locations, Journal of the Atmospheric Sciences 59 (2002) 590-608. URL: https : //doi .org/10.1175/1520-0469(2002) 059<0590:VOAAOP>2 . 0 . CO; 2. doi:10.1175/1520-0469(2002)059¡0590:VOAAOP ¿2.0.CO;2. 
[26] O. Dubovik, A. Sinyuk, T. Lapyonok, B. N. Holben, M. Mishchenko, P. Yang, T. F. Eck, H. Volten, O. Muñoz, B. Veihelmann, W. J. van der Zande, J.-F. Leon, M. Sorokin, I. Slutsker, Application of spheroid models to account for aerosol particle nonsphericity in remote sensing of desert dust, Journal of Geophysical Research: Atmospheres 111 (2006). URL: https: //agupubs . onlinelibrary . wiley.com/doi/abs/10.1029/2005JD006619. doi:10.1029/2005JD006619.

[27] D. M. Giles, A. Sinyuk, M. G. Sorokin, J. S. Schafer, A. Smirnov, I. Slutsker, T. F. Eck, B. N. Holben, J. R. Lewis, J. R. Campbell, E. J. Welton, S. V. Korkin, A. I. Lyapustin, Advancements in the aerosol robotic network (aeronet) version 3 database - automated near-real-time quality control algorithm with improved cloud screening for sun photometer aerosol optical depth (aod) measurements, Atmospheric Measurement Techniques 12 (2019) 169-209. URL: https ://www . atmos-meas-tech . net/12/169/2019/. doi:10.5194/amt12-169-2019.

[28] A. F. Stein, R. R. Draxler, G. D. Rolph, B. J. B. Stunder, M. D. Cohen, F. Ngan, Noaa's hysplit atmospheric transport and dispersion modeling system, Bulletin of the American Meteorological Society 96 (2015) 2059-2077. URL: https://doi.org/10.1175/BAMS-D-14-00110.1. doi:10.1175/BAMSD-14-00110.1. arXiv:https://doi.org/10.1175/BAMS-D-14-00110.1. 